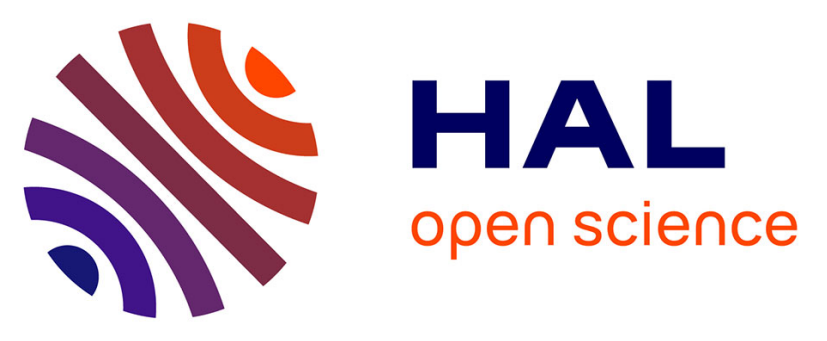

\title{
AirMeet: Communication Support System by Temporarily Sharing Personal Information for Social Gathering
}

Rina Kotake, Kazuma Kimura, Akiko Kawabata, Go Sato, Momoka Shiohara, Junichi Hoshino

\section{To cite this version:}

Rina Kotake, Kazuma Kimura, Akiko Kawabata, Go Sato, Momoka Shiohara, et al.. AirMeet: Communication Support System by Temporarily Sharing Personal Information for Social Gathering. 16th International Conference on Entertainment Computing (ICEC), Sep 2017, Tsukuba City, Japan. pp.409-413, 10.1007/978-3-319-66715-7_51 . hal-01771300

\author{
HAL Id: hal-01771300 \\ https://hal.inria.fr/hal-01771300
}

Submitted on 19 Apr 2018

HAL is a multi-disciplinary open access archive for the deposit and dissemination of scientific research documents, whether they are published or not. The documents may come from teaching and research institutions in France or abroad, or from public or private research centers.
L'archive ouverte pluridisciplinaire HAL, est destinée au dépôt et à la diffusion de documents scientifiques de niveau recherche, publiés ou non, émanant des établissements d'enseignement et de recherche français ou étrangers, des laboratoires publics ou privés. 


\title{
AirMeet: Communication Support System by Temporarily Sharing Personal Information for Social Gathering
}

\author{
Rina Kotake ${ }^{1}$, Kazuma Kimura, Akiko Kawabata, \\ Go Sato, Momoka Shiohara, Junichi Hoshino ${ }^{1}$ \\ ${ }^{1}$ University of Tsukuba, Entertainment Computing Lab, \\ 1-1-1, Tennodai, Tsukuba-shi, Ibaraki, Japan \\ kotake.rina@entcomp.esys.tsukuba.ac.jp,jhoshino@esys.tsukuba.ac.jp
}

\begin{abstract}
In this paper, we propose a system "AirMeet" that supports temporary communication within the venue of the social gathering by limiting personal information to be shared at the time of the social gathering according to its purposes. As a result of carrying out the experiment at the social gatherings, we confirmed that we can promote sharing within the boundary of meeting venue by limiting the personal information participants had not disclosed on the Web. In addition, it confirmed that communication is supported by sharing personal information according to the purpose of the social gathering and using the application in the venue, and it showed the usefulness of the application
\end{abstract}

Keywords: Social gathering, Communication support, Personal Information

\section{Introduction}

A "social gathering" is regarded important that supports new connections by collecting many people who are first meeting. However, in the real world, it is difficult to find a chance to start conversation with the other person as personal information is invisible. Here, it sometimes helps solve problems by distributing nameplates containing personal information and hanging them from necks of the individuals. In order to make a chance of conversation at academic meetings or exhibitions for example, personal information according to the purpose of a social gathering such as "contents of presentation" that may be a trigger of conversation is written in many cases on the nameplate. In addition, the nameplate can be viewed only by people inside the social gathering, realizing privacy protection in places where many and unspecified people gather.

However, there are problems in the limited amount of information that can be written, or problems that the written information is visible only from close distance. Therefore, in this paper we propose a system "AirMeet" that supports communication by temporarily sharing personal information that should be shared at that time according to the purpose of the social gathering only to people in the social gathering venue. As of April 2017, iOS application "AirMeet" which used part of the result of this paper is open to the public (http://airmeet.tk/).

\section{System Overview}

AirMeet is a smartphone application with low introduction cost which expands the function of the nameplate distributed at the social gathering. An outline of the system is shown in Fig. 1. 


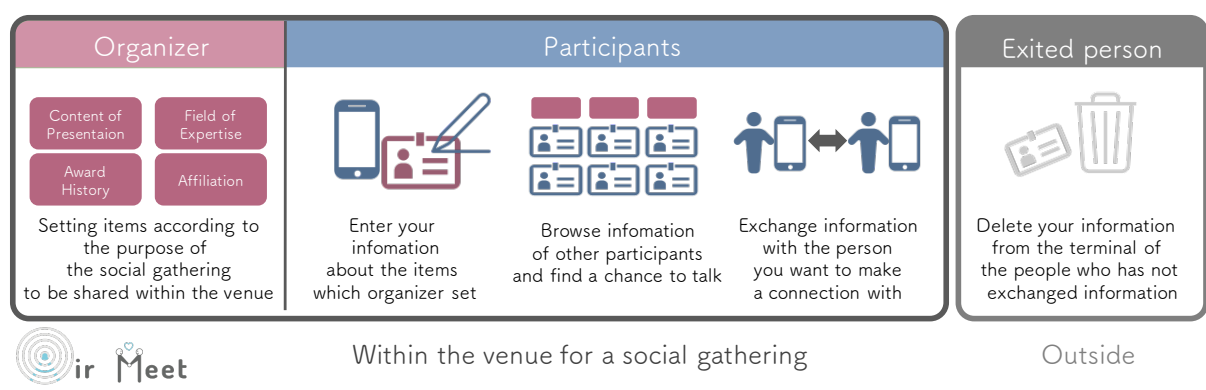

Fig. 1. Outline of System

The organizer of the social gathering has a role of establishing items of personal information to be shared at the place and at the time according to the purpose of the social gathering and a role of judging whether participants are inside the meeting venue.

At the social gathering, after participants enter the profile information to be shared within the meeting place, they see the profile information of other participants on the screen shown in Fig. 2 and discover a person whom he/she wishes to communicate with and triggers a conversation. This is supposed be how it works. Also, in order to support creating connections, there is a "MEET function" that exchanges profile information with the person who communicated.

When a participant exit from the venue, information shared with other smartphone terminals and servers is automatically deleted, and information on other participants is deleted also from the smartphone terminal of the participant exited. At that time in case "MEET function" had been used for exchanges of profile information with the person, the information on the smartphone terminal of the person with whom he/she had been communicating will not be deleted. The configuration of the installed system is shown in Fig. 2, and the explanation below is added.

[1] Register the venue information from the terminal possessed by the organizer through HTTP communication.

[2] The organizer's terminal is responsible for determining whether participants are in the venue by use of beacon communication.

[3] When it is determined that the participant is in the venue, HTTP communicates reception of venue information, sharing and exchange of personal information.

[4] When it is judged the person is not in the venue, it will disconnect communication and erase personal information from the database on the server side.

[5] Information exchanged is stored in the client database.

\section{Experiments}

We conducted an operational experiment at two social gatherings held on the night of the first and second days of the 2 nights / 3 days overnight workshop conducted by the Japan Software Society Interactive System and Software (ISS) Study Group. The results are described below. 

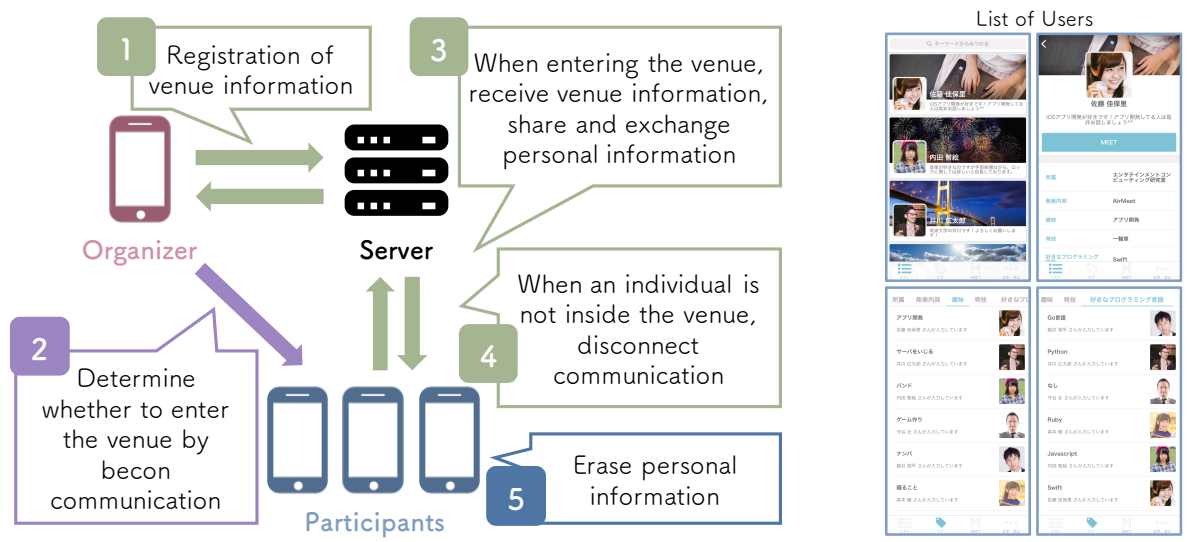

Fig. 2. System configuration and system screen

Profile information shared within the venue is judged and set by the author to activate discussion and communication that would serve the purpose of the social gathering held during the workshop, namely "company / school" "job title / grade" "research field", "presentation title", " trademark gag ", "favorite programming language". Regarding the usage of the application, 72 of the 162 participants in the workshop owned the iOS terminal and agreed to cooperate launched the application. There were 44 participants on the first day and 29 on the second day and 19 participated on both days, totaling 54 who offered cooperation in the event to enter the profile information. 38 people used the MEET function.

Described results of questionnaire after using / application for cooperators who participated in the event. The evaluator was 9 people ( 3 males and 6 females) with ages 22 to 43 (average age 27.8, standard deviation \pm 11.3 ). In order to verify whether participants can promote sharing of personal information in the confined venue, we have set questions on each item about the scope of disclosure of profile information on the Web, and summarized the input situation to applications as shown in Fig. 3 [A]. In all the items, there were evaluators who entered profile information to the application, which they make limitedly public or undisclosed on the Web.

As "information is shared only among the people who are at the place and not remaining on the Web" etc., sense of security is obtained by allowing share of information in a controlled manner at limited place and time in a natural way. Comments were given indicating the usefulness of information sharing limited in a venue for a temporary time.

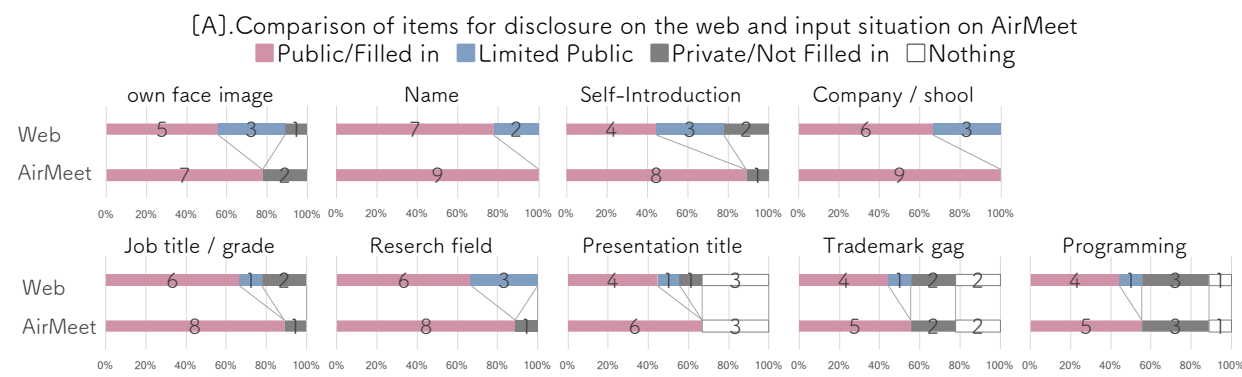

Fig. 3. Survey results : Can promote the sharing of personal information through information sharing was limited at the social gathering? 
In order to verify whether it will be supporting communication by sharing personal information according to the purpose of the social gathering, [B] Whether there was someone who wanted to talk to looking at the information available on the application and was able to talk actually, [C] Whether it has been possible to establish a connection; Result of these questions are summarized in Fig. 4.

[B] There were 7 evaluators out of 9 who saw the information on the application and wanted to talk to them, and among them 6 evaluators who were able to speak to them actually. In the free description of the evaluator who had someone whom he/she wanted to speak to, it was noted that he/she wanted to talk to looking at profile items such as "face photograph", "job title / grade", "research field" and "presentation content", and it was confirmed that sharing the characteristic personal information according to the purpose of the social gathering will be helpful in communication support at the social gathering. In addition, there was a dialogue asking / being asked "if you are using AirMeet?" indicating that use of an application became a trigger of conversation.

[C] Seven of the nine evaluators were able to make a connection at least once at this social gathering, and six of the evaluators used the application. In order to make a connection with Facebook communication in the real world, it is necessary to search the name with an accurate notation and search for the other party. In this application, there were many advantages as being able to easily make connections using the MEET function on condition that they are inside the venue.

[B].Were you able to speak to someone?

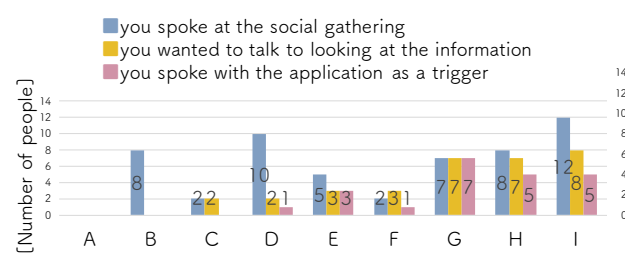

[C].Could you make a connection

Eyou made connection on this social gathering you made connection using the application

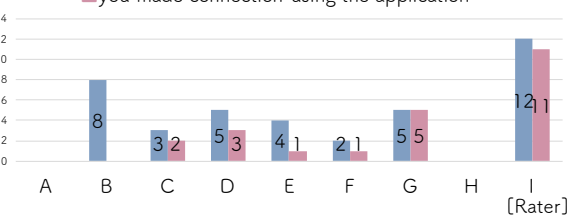

Fig. 4. Survey results : Can support communication by sharing personal information according to the purpose of the social gathering?

\section{Conclusion}

We proposed AirMeet which temporarily shares personal information according to the purpose of the social gathering only to the people inside the social gathering venue. By conducting the experiment at the social gathering and limiting the Web restricted profile information to stay only within the venue to be shared by the participants, it has been confirmed that the sharing can be promoted by participants.

In addition, we have clarified that it will support communication by sharing participants' profile information according to the purpose of the social gathering and using the application within the venue.

\section{References}

1. R. Kotake, J. Hoshino. AirMeet : Communication Support System for Social Gathering. HCI, IPSJ, Vol.172 No.11, 2017 (in Japanese). 